Meijer, A., Campen, C. van, Kerkstra, A.

A comparative study of the financing, provision and quality of care in nursing homes: the approach of four

European countries: Belgium, Denmark, Germany and the Netherlands.

Journal of Advanced Nursing: 32, 2000, nr. 3, p. p. 554-561

\begin{tabular}{l|l|}
$\begin{array}{l}\text { Postprint Version } \\
\text { Journal website }\end{array}$ & 1.0 \\
\hline Pubmed link & $\underline{\text { http://www.//wwww.ncbi.nlm.nih.gov/entrez/query.fcgi?cmd=Retrieve\&db=pubmed\&dop }}$ \\
DOI & $\underline{\mathrm{t}=\text { Abstract\&list_uids=11012796\&query_hl=20\&itool=pubmed_docsum }}$ \\
\hline
\end{tabular}

Correspondence: A. Kerkstra, Netherlands Institute of Primary Health Care (NIVEL), PO Box 1568, 3500 BN Utrecht, The Netherlands. E-mail: a.kerkstra@nivel.nl

\title{
A comparative study of the financing, provision and quality of care in nursing homes. The approach of four European countries: Belgium, Denmark, Germany and the Netherlands
}

\author{
ASTRID MEIJER MSC - Research Assistant, \\ Department of Nursing and Caring Research, Netherlands Institute of Primary Health Care \\ CRÉTIEN VAN CAMPEN PHD - Research Fellow, \\ Department of Nursing and Caring Research, Netherlands Institute of Primary Health Care
}

ADA KERKSTRA PHD - Head of the Department of Nursing and Caring Research, Netherlands Institute of Primary Health Care, Utrecht, The Netherlands

\begin{abstract}
As result of an increase in the numbers of frail elderly people, most European countries are facing problems with the financing and provision of services by nursing homes. At the same time, the expectations of quality of these services continue to rise. The main question investigated in this study was that of how countries approach the problems of financing and service provision by nursing homes and, at the same time, attempt to increase the quality levels in these institutions. The study was conducted in Belgium, Denmark, Germany and the Netherlands. A study was made of the relevant literature and questionnaires were sent to experts in each country. The four countries are addressing the problems of financing and sufficient service provision by controlling the use of nursing home services. In addition, financial problems are approached by extending co-payments, encouraging cheaper forms of care and putting pressure on nursing homes to operate at lower costs. Problems in the provision of care are addressed by applying more selective admission criteria and offering alternative forms of care outside the nursing home. As a result nursing home beds are used for those with the greatest care-dependency. Nursing home services are adjusted to rising quality expectations by offering a greater range of provision, decreasing the number of residents per room, improving comfort and improving the training of nursing staff. Another way to increase the quality of care is to separate the housing and service functions. Many nursing homes nowadays collaborate intensively with other facilities for the elderly to cope with all these problems and
\end{abstract}


Meijer, A., Campen, C. van, Kerkstra, A.

A comparative study of the financing, provision and quality of care in nursing homes: the approach of four European countries: Belgium, Denmark, Germany and the Netherlands.

Journal of Advanced Nursing: 32, 2000, nr. 3, p. p. 554-561

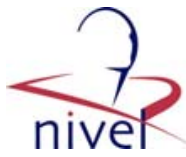

changes. The workload for nursing home staff has increased because of the increasing care-dependency of residents, the demand for higher quality of services and the financial problems.

\section{INTRODUCTION}

The increase in the numbers of elderly people (65 years and above) and especially of elderly people of 80 and above, who generally have a higher level of disability, secondary to multiple chronic diseases, has resulted in a marked growth in the demand for long-term care. It is expected that there will be an even greater need for such services in the future. As a consequence, care for elderly people has become a policy priority in many European countries. New services, or more extensive provision of some existing services for frail elderly people, will be required as a result of these demographic changes. There is also concern about the expenditure on care for elderly people being supported by a proportionally smaller working population. For this reason, reducing expenditure on care for elderly people has high priority. At the same time, quality expectations continue to rise. Nowadays, services are expected to meet the specific needs of the individual elderly person (Sundstrom et al. 1994). This brings about a tension between efforts to improve quality and the limitations imposed by the funding and provision actually available.

The main research question in this study was: How do countries deal with problems of reducing expenditure and providing sufficient services in long-term residential care for frail elderly people and, at the same time, attempt to improve the quality of these services?

Within the broad range of residential care facilities, the focus is on nursing homes. The reason for this is that nursing homes provide care for elderly people with the greatest care-dependency. This results in nursing homes bearing the brunt of the growing numbers of frail elderly people. Nursing homes mainly provide care for elderly people with chronic diseases, disabilities, either physical or mental (mainly dementia) or both. In this study a nursing home was defined as an institution providing 24-hour nursing care, ADL (activiities of daily living) assistance and mobility, psychosocial and personal care. Also provided is paramedical care, such as physiotherapy and occupational therapy and room and board (Ribbe et al. 1997). Residential homes for elderly people (homes for the aged), hostels, sheltered housing and geriatric wards in hospitals were excluded from this study.

There have been several studies that compare developments within the field of care of elderly people in different countries (Jamieson \& Illsley 1990, Wilderom et al. 1990, 1991b, 1993, Evers \& Svetlik 1991a, Kraan et al. 1991, Nijkamp et al. 1991, Giarchi 1996; de Boer \& Roose 1997, Rostgaard \& Fridberg 1998). However, they focus on care of elderly people as a whole, and in general only give a brief description of developments within the specific field of nursing homes. Ribbe et al. (1997) focus explicitly on nursing homes, with an analysis of the relation between the ageing status of a country and the number of nursing home beds. Nevertheless, as far as is known, there are no recent publications that include both the problems of financing and provision, as well as the policy of improving quality with the restrictions imposed by these problems.

For the purposes of this research, the four countries are compared on general aspects, financing, care provision and quality of care. The balance between government regulation and self-regulation is considered to provide information about the regulatory environment in the specific countries. The funding of nursing homes is considered in terms of the type of insurance for admission to a nursing home and the amount of user charge that has to be paid. With regard to the provision of services, the countries are compared on the presence of waiting lists, the substitution policy that is pursued and cooperation with other organizations. Furthermore, initiatives to improve the quality of nursing homes in the different countries are compared. Cooperation with other organizations also plays a role in these initiatives. Recent developments and problems are discussed. In this way, insight is gained into the situation of nursing homes in these countries and into the way financing and provision problems are addressed and the quality of service is improved. 


\section{METHODS}

This study was conducted in Belgium, Denmark, Germany and the Netherlands. Because of limited means and time available, this study was restricted to four countries. These countries were selected because of their relatively well-developed health care systems and their rapidly ageing populations. There are countries with a 'Bismarck' (insurance based) system represented as well as Denmark, with a national health service (NHS) (tax based) system. Information about these countries was expected to be found in the literature, and we expected that there would be (English speaking) experts willing to provide additional information. Following Hutten \& Kerkstra (1996) who investigated the organization and financing of home care in Europe, two complementary research methods were used:

\section{Desk research}

The study started with literature research in Netherlands Institute of Primary Health Care (NIVEL) files. Data were assembled from recent comparative studies, government documents, statistical yearbooks and articles in journals. Further literature was collected via references in the literature. This provided a general description of the health care system in each country. There were only a limited number of references on our general research topic and there was almost no information on the financing of nursing homes.

\section{Postal questionnaire to experts}

In each country, experts on nursing homes were contacted. Potential experts were selected from NIVEL contacts, the RAI-network (an international network on the Resident Assessment Instrument) and the literature. Experts had to be from one of the four countries included, be experts in the field of nursing homes and have an overview of the situation in their country. Belgium and Denmark were each represented by three experts. Germany and the Netherlands were each represented by two experts. Most experts are academic researchers in the field of care of elderly people.

The questionnaires, in English, were sent to all participating experts at the beginning of 1998. The questionnaires consisted of questions concerning general aspects, financing, care provision and quality of care. The general questions were on the organization and financing of nursing homes. The specific questions considered the way people were insured for the costs of admission to a nursing home, the amount of user charge that had to be paid, the balance of government-regulation and self-regulation, the substitution policy that was pursued, the presence of waiting lists, initiatives to improve quality and cooperation with other organizations. Furthermore, all experts were asked to describe recent developments and problems in the field of nursing homes in their country. In this way, recent reforms were recorded.

When quantitative information was required, the most recent concrete figures based on official statistics or research results were preferred. However, if such published information was not available in a country, participants were asked to make their own estimate. Experts were asked to add literature on the situation in their country. Furthermore, some experts were contacted for additional information or because the information that was provided was unclear, for instance when experts from the same country gave different answers to the same question.

The type and amount of information differed between the countries. It was extremely difficult to gather data on a national level, for Belgium and Denmark, as there is a dearth of organizations collecting statistical data on nursing homes on a national level.

After all the information had been collected, a draft description for each country was written and returned to the experts for corrections and additions. If no specific source is mentioned, the information comes from answers to the questionnaires. 


\section{RESULTS}

\section{The setting}

All countries in this study are developed nations with high life expectancy. In all countries, the support ratio (number of elderly per 100 younger adults) is high and increasing rapidly. The figures in Table 1 represent the essential characteristics of the populations in Belgium, Denmark, Germany and the Netherlands. Although the process of ageing, which determines the provision of services for older people, is characteristic of Europe as a whole, there are differences between the four countries. The percentage of older people is very high in Belgium and Germany and moderate in Denmark, with the Netherlands lagging behind.

\section{[ TABLE 1 ]}

Each country has its own way of organizing and financing health care, but generally in all four countries health care and services for the elderly are relatively well developed. Institutionalization rates among the nations differ, due at least in part to differences in the organization and financing of long-term care services, in the amount of responsibility assumed in the care for disabled elderly people by each sector and the availability of long-term care beds.

In Belgium, until the beginning of the 1980s, there were no nursing home facilities. Nowadays nursing home services are in distinct parts of hospitals or homes for the aged. A nursing home bed can only be created if an acute hospital bed is closed. Of the nursing home beds, $67 \%$ are in old age people's homes and the rest are connected with hospitals (Lammertijn 1990). A nursing home bed connected with a hospital is not the same as a bed in the geriatric ward of a hospital. As has been mentioned above, geriatric wards were not included in this study.

Denmark has a relatively large stock of specialist housing for elderly people. However, this country is also active in seeking alternatives to nursing homes in the form of self-contained dwellings (de Boer \& Roose 1997). Since the passing of the Housing for the Elderly Act in 1987, traditional nursing homes continue to be closed at a rate of approximately 10\% per year (Ribbe et al. 1997). Nursing home services are now provided by new-style housing for elderly people, but there are also traditional homes.

In Germany institutional homes for older people are places of last resort. Institutional development concerns the construction of multipurpose homes (Mehrgliedrige Einrichtungen). The capacity of these homes is growing and usually includes service flats, homes for the aged and nursing homes on the same site (de Boer \& Roose 1997).

The Netherlands has a relatively high percentage of older people living in institutions; around $7 \%$ of older people live in residential homes and $2.5 \%$ in nursing homes (de Boer \& Roose 1997). Most nursing homes are independent institutions but many nursing homes now form federations or merge with homes for the aged (Ribbe 1993).

When the balance between government-regulation and self-regulation is considered, the following is found. In Denmark and the Netherlands all nursing homes operate on a non-profit basis (Table 2). In Belgium 20\% and in Germany 26\% of the nursing homes operate on a for-profit basis. In three countries nursing homes are mainly run by private non-profit organizations, such as religious organizations and charities; except for Denmark, where the majority of nursing homes are run by the local authorities. In Belgium nursing homes are under the responsibility of the three linguistic communities (Flanders, the Walloon Region and Brussels). In Germany the 16 Federal States (Länder) and nursing insurance (Pflegeversicherung) are responsible for the provision of nursing home services. In the Netherlands, the 13 provinces are responsible for the planning of nursing homes (Hutten \& Kerkstra 1996). Due to different economic and political contexts there can be local differences within each country. 


\section{[ TABLE 2 ]}

In general in all four countries, nursing homes are intended for elderly people who have long-term disorders and those with greatest care-dependency. Despite identical objectives, these services are offered in different forms and under different country-specific conditions. The characteristics of nursing homes, staff and patient populations are shown for each country in Table 3. In most countries, the average number of beds per nursing home lies between 30 and 46. In the Netherlands, however, the average number of beds per nursing home is 170 (Spaan \& Bartels 1998). The average age of residents in nursing homes in three countries is above 80 . The majority of nursing home residents $(>70 \%)$ are women and the average age of the women is higher than the men's.

\section{[ TABLE 3 ]}

The distribution of somatic residents (residents with physical health problems) and psycho-geriatric residents (residents with dementia or other psychiatric problems as primary diagnosis) differs per country. In Germany and the Netherlands, the distribution of somatic and psychogeriatric residents is almost equal. In Belgium the majority (70\%) of residents have somatic problems. The most important functions of nursing homes are long-term care and terminal care but other services such as respite care for residents' families and day care are also provided. The average length of stay varies from 1.4 years in the Netherlands (Ribbe et al. 1997) to 3.5 years in Belgium. Generally, the average length of stay is longer for psychogeriatric residents than for somatic residents. Many nursing home residents eventually die in the nursing home or after a short stay in a hospital. In the Netherlands, however, due to intensive rehabilitative efforts, approximately one out of three residents (35\%) are discharged (Ribbe 1993). Many of them are discharged to a home for the aged. Nursing homes in the other three countries do not provide such extensive rehabilitative services. In Belgium, Denmark and Germany somatic and psychogeriatric residents are mostly cared for in the same institutions and wards. In contrast, in the Netherlands they are cared for in separate wards or in separate institutions (Ribbe 1993).

\section{Financing}

In Belgium a health insurance contribution and special nursing insurance in Germany cover the costs of nursing care. The level of reimbursement paid by the insurer depends on the level of caredependency in terms of assessment on a care dependency scale. Board and lodging are paid for by the elderly themselves. In Belgium the elderly sometimes have to pay supplements depending on their level of care-dependency and for several services and materials. Nursing homes in both countries are funded by the regional authorities for the building, renovation and furnishing of institutions. In Denmark, all nursing home services are financed by general taxation. The elderly pay for electricity, heating and rent but, apart from this, they only pay for the extra services they use. All those domiciled in the Netherlands are insured for the costs of care in a nursing home through the Exceptional Medical Expenses Act (AWBZ). Furthermore, residents pay an income-dependent contribution (Voorlichtingscentrum Sociale Verzekering 1997).

As mentioned in the introduction, the countries in this study are experiencing problems regarding the financing of long-term care for elderly people. To a degree, the welfare systems of the countries in this study constitute a commitment by the state to meet the welfare needs of elderly people. The huge increases in the aged dependency ratios over the next 50 years form a major fiscal threat. Consequently, all four countries are reviewing their payment structures and charging policies for services. In the four countries studied, the solutions for the financial problems are mostly found in the introduction of more market-and self-regulation. At present, many countries are still heavily reliant on the state and society for the financial basis of long-term care and will most likely be so in the future, albeit with a higher private participation and a more selective admission policy with regard to the use of services. A prime example of this is the introduction of nursing insurance (Pflegeversicherung) in 
Germany, which insures everyone for the costs of longterm nursing care, comparable with regulations in the Netherlands. As a result of the introduction of this nursing insurance, the roles and functions of the different actors in the field have altered and more selective admission criteria are applied. An aim of the new insurance is also to increase competition among nursing homes in order to promote higher quality and lower costs.

All four countries control the use of nursing home beds and in consequence the costs too. The authorities are encouraging cheaper forms of care, such as elderly people living in their own homes as long as possible. Denmark developed its thinking in this area early on. In the 1960s they saw the growth of central government expenditure as an impending problem and began to introduce legislation to counteract this growth. A shift in ageing policy has been applied as part of a decentralization and de-institutionalization process since the 1960s. De-institutionalization in Denmark includes the move from expensive to less expensive care; from residential care to community care. To promote and encourage this trend, in 1987 the elderly people's housing reform bill was passed. The act prohibited the building of new nursing homes. As an alternative, a new housing type, the new-style flats for the elderly was introduced and attracted high levels of public subsidy. In addition, the provision of home help and personal nursing care has been extended (de Boer \& Roose 1997).

In all four countries, market elements such as user charges for nursing home services are being introduced or extended. In this way, people are encouraged to make use of services more selectively. This increase is not, as it was in the past, primarily aimed at reducing the use of services, but also at shifting the burden from the public to the private sector. In Belgium and Germany the income of residents is not always sufficient to pay the contribution for accommodation they have to pay. In all four countries nursing homes are under great pressure to work at lower costs. In Belgium, for example, insurance companies pay little for nursing homes. Due to a shortage of federal funding, there are also problems in paying for the housing facilities (Hutten \& Sixma 1996).

\section{Provision of services}

As a result of the increasing demand for nursing home care several problems have arisen. When health care resources are scarce, waiting lists may be used as a means of rationing in order to enhance the fair allocation of resources by selection of patients (Meiland et al. 1996). In most of the countries in this study, nursing homes have waiting lists. In the Netherlands and Belgium, many nursing homes have waiting lists, and in particular for facilities for psycho-geriatric residents. In Belgium waiting lists can differ greatly between regions (Raymaekers 1990). In Denmark waiting lists are now decreasing due to expansion of the housing stock for elderly people. In Germany, after the introduction of the nursing insurance in 1996, waiting lists first turned very short, but 2 years later most nursing homes again had waiting lists as before.

Consequently, eligibility criteria and assessments for services are tightening. In all four countries the elderly need a referral from an assessment committee or a physician. There are generally standardized rules for assessment. In most countries in this study, admission policies have become more selective. In order to postpone admission to a nursing home, elderly people are encouraged to live in their own homes for as long as possible.

Nursing homes are developing alternative forms of care to fulfil the need for nursing home care outside the nursing homes: this is called substitution-policy. In these projects nursing homes collaborate with other organizations for care for elderly people. In Denmark, Germany and the Netherlands, many nursing home beds are in so called combined institutions, institutions that contain a nursing home, homes for the aged and/or sheltered housing. In these countries the collaboration between different facilities for elderly people is intense. In the Netherlands there are projects for substitution of nursing home care to the community. There also is collaboration with hospitals regarding short-term rehabilitation and continuation of care (Ribbe 1993). Although in Belgium nursing homes are part of an old age home or hospital, officially there is no collaboration with other organizations that provide care for elderly people. However, in some places there are regular consultations between geriatric departments of hospitals and nursing homes. 


\section{Staff categories}

In all four countries there are nurses and nursing assistants working in nursing homes. Nurses have usually had specific training for at least 2 years or more. Nurses mostly perform all technical nursing tasks. Nursing assistants mainly perform tasks of basic nursing (washing, etc.) and no medical or pharmaceutical tasks as the nurses do. The majority of nursing assistants have had only limited training. In most countries in this study, medical treatment in nursing homes is provided by general practitioners. Only in the Netherlands is the medical care in nursing homes provided by specially trained nursing home physicians. In most countries in this study, the paramedical staff of nursing homes consist of physiotherapists, social workers, activity and occupational therapists. There are large differences between the countries regarding the number and type of paramedical staff working in nursing homes. In Denmark for instance the number of paramedical staff working in nursing homes is very limited. In the Netherlands paramedical staff consist of many different types of therapists (Ribbe 1993).

\section{Quality}

The expectations that elderly people have regarding the quality of services they receive has increased. Also, attitudes towards elderly people have changed to more of one as consumer rather than patient. As a result of these developments, there are initiatives to increase the quality of nursing home services and to adjust services to the wishes of the present-day elderly. More attention is being paid to the opinion of residents. In all countries many nursing homes have organized residents' committees. In the case of residents with dementia this is often replaced by a family committee.

The range of provisions has also become more differentiated and there are initiatives to separate the housing and service functions of nursing homes in order to meet the individual needs of residents.

The care service in the new-style flats for elderly people in Denmark is adjusted over time to meet the needs of the elderly person in question. Due to the separation of the housing and the service function, people now can stay in their own apartments and do not have to move as their need for care changes. Residents only use the services they need and care can be adjusted to individual needs. It also gives the resident more freedom of choice with regard to the services that are used (Nijkamp et al. 1991). Separation of the housing and service function also occurs in the Netherlands. In general the importance of day care is increasing. In Germany there are special short-term nursing homes.

Furthermore, in general, the number of residents per room is being decreased and the comfort is being upgraded. The number of residents per room in general varies between one and four. The number of one- and two person rooms is increasing. There are very seldom more than four residents in one room. In Denmark almost all residents stay in a single room. In the new-style housing for elderly people the housing function is upgraded to a two-room flat with modern comfort, designed for the disabled.

\section{Staff education}

Another initiative to increase quality of care is improving the education of the nursing staff. A few years ago in Belgium and Denmark special education was developed for staff working in care of elderly people. In Belgium an option for special training in geriatric nursing has also been created. In Denmark a basic educational training programme for all staff in the hospitals and caring sector for elderly people has been introduced. The basic training takes 1 year. After another 1 . years, graduates of the course work as assistant nurses or in the home help service. After a few more years of education and training they can work as nurses or continue to specialize in related areas (Nijkamp et al. 1991). Many municipalities have integrated staff. The same staff take care of elderly people, within the remaining nursing homes and in the general housing.

Due to the increasing care-dependency of residents, the demand for higher quality of services and the financial problems, the workload for nursing home staff has increased. In the Netherlands this is a common complaint heard from nursing home staff and nursing home management. 


\section{CONCLUSIONS}

This study has taken a step in the direction of defining how four European countries address similar problems occurring in the field of nursing homes. The main question in this study was how countries address the problems of financing and provision of services by nursing homes, and at the same time attempt to increase the level of quality of care by these institutions. All four countries generally apply the same methods, but not all countries have made the same progress or been equally successful.

Governments address the financial problems mainly by controlling the use of nursing home services, putting pressure on nursing homes to operate at lower costs, and encouraging cheaper forms of care, by introducing or extending user charges and by stricter admission criteria. As a result, the caredependency of residents has increased and nursing homes have less funding, resulting in increased work pressure on nursing home staff. To cope with the problem of providing sufficient nursing home care, nursing homes are developing alternative forms of care to fulfil the need for nursing home care outside the nursing home: this is called a substitution-policy. Nursing home services are adjusting to the rising expectations regarding quality by offering a greater range of provision, decreasing the number of residents per room, and improving comfort. Furthermore the education of nursing staff is being improved. Another way to improve the quality of care is to separate the housing and service functions, so that people do not have to move when their need for care changes and the care can be adjusted to the needs of the individual resident. To cope with all of these problems and changes, many nursing homes nowadays collaborate intensively with other facilities for elderly people. Consequently the traditional nursing home as an independent institution is disappearing.

It seems that innovative projects help nursing homes to deal with the problems of financing and provision of sufficient service and also improve quality, but at the same time waiting lists and the work pressure on the nursing staff have increased. This makes clear the importance of anticipating possible negative or unintended consequences of policy measures, so that the solutions for existing problems do not create new problems of their own. It is also doubtful if today's creative and innovative solutions will be sufficient to address problems in the future.

\section{REFERENCES}

de Boer A. \& Roose T. (1997) Housing \& Care Services for Older People: European Policy Trend Report 1997. HOPE Network, Kidlington. Housing for Older People in Europe, S.L.

Evers A. \& Svetlik I. (1991a) New Welfare Mixes in Care for the Elderly, 2: Austria, Denmark, Finland, Israel, Netherlands. European Centre for Social Welfare Policy and Research, Vienna.

Evers A. \& Svetlik I. (1991b) New Welfare Mixes in Care for the Elderly, 3: Canada, France, Germany, Italy, United Kingdom. European Centre for Social Welfare Policy and Research, Vienna.

Evers A. \& Svetlik I. (1993) Balancing Pluralism: New Welfare Mixes in Care for the Elderly. Ashgate, Aldershot.

Giarchi G.G. (1996) Caring for Older Europeans: Comparative Studies in 29 Countries. Arena, Aldershot.

Hutten J.B.F. \& Kerkstra A. (1996) Home Care in Europe: A Country Specific Guide to its Organization and Financing. Arena, Aldershot.

Hutten J. \& Sixma H. (1996) Primary Health Care for Elderly People in Europe: A Description of its Structure and Function in Seven European Countries. NIVEL, Utrecht.

Jamieson A. \& Illsley R. (1990) Contrasting European Policies for the Care of Older People. Avebury, Aldershot.

Kerkstra A. \& Hutten J.B.F. (1996) Organization and financing of home nursing in the European Union. Journal of Advanced Nursing 24, 1023-1032.

Kraan R.J., Baldock J., Davies B., Evers A. \& Johansson L. (1991) Care for the Elderly: Significant Innovations in Three European Countries. Campus, Frankfurt am Main. 
Meijer, A., Campen, C. van, Kerkstra, A.

A comparative study of the financing, provision and quality of care in nursing homes: the approach of four European countries: Belgium, Denmark, Germany and the Netherlands.

Journal of Advanced Nursing: 32, 2000, nr. 3, p. p. 554-561

Lammertijn F. (1990) De welzijnszorg in de Vlaamse gemeenschap: voorzieningen en overheidsbeleid. (Welfare Service in the 3 Flemish Community: Facilities and Government Policy) Department of Sociology, Catholic University Leuven, Leuven.

Meiland F.J.M., Danse J.A.C., Hoos A.M., Wendte J.F. \& Gunning- Schepers L.J. (1996) The use of the waiting list in a fair selection of patients for nursing home care. Health Policy 38, 1-11.

Nijkamp P., Pacolet J., Spinnewijn H. et al. (1991) Services for the Elderly in Europe: A Cross-National Comparative Study. HIVA/ VU, Leuven.

Organization for Economic Co-operation and Development (1998) Health Data 1998. A Comparative Analysis of 29 Countries. OECD, Paris.

Raymaekers P. (1990) De spreiding van de intramurale bejaardenzorg in Vlaanderen (The distribution of intramural elderly care in Flanders). Sociaal 11(3), 6-8.

Ribbe M.W. (1993) Care for the elderly: the role of the nursing home in the Dutch health care system. International Psychogeriatrics 5, 213-222.

Ribbe M.W., Ljunggren G., Steel K. et al. (1997) Nursing homes in 10 nations: a comparison between countries and settings. Age and Ageing 16, 3-12.

Rostgaard T. \& Fridberg T. (1998) Caring for Children and Older People: A Comparison of European Policies and Practices. Danish National Institute of Social Research, Copenhagen.

Spaan J.M. \& Bartels L.P. (1998) Verpleeghuiszorg in cijfers 1992- 96. Nederlandse Vereniging voor Verpleeghuiszorg (NVVz), Utrecht.

Sundstrom G., Tinker A., Wiener J. \& Davies B. (1994) Caring for Frail Elderly People: New Directions in Care. Organization for Economic Co-operation and Development, Paris.

Voorlichtingscentrum Sociale Verzekering. (1997) De Kleine Gids Voor de Nederlandse Sociale Zekerheid 1997 (The Small Guide for the Dutch Social Security). Kluwer, Deventer.

Wilderom C.P.M., Nijkamp P. \& Vollering A.M.C. (1990) Services for the Elderly in Europe: A CrossNational Comparative Analysis. Vrije Universiteit, Amsterdam

\section{TABLES}

Table 1 Population key figures

\begin{tabular}{|c|c|c|c|c|}
\hline & Belgium & Denmark & Germany & $\begin{array}{l}\text { The } \\
\text { Netherlands }\end{array}$ \\
\hline Population in millions & $10 \cdot 192$ & $5 \cdot 295$ & $82 \cdot 06$ & $15 \cdot 650$ \\
\hline$\%$ over 65 years & $16 \cdot 5$ & $14 \cdot 9$ & $15 \cdot 8$ & $13 \cdot 5$ \\
\hline Life exp. men (years) & $73 \cdot 8$ & $73 \cdot 0$ & $73 \cdot 7$ & $74 \cdot 7$ \\
\hline $\begin{array}{l}\text { Life exp. women } \\
\quad \text { (years) }\end{array}$ & $80 \cdot 5$ & $78 \cdot 2$ & $80 \cdot 0$ & $80 \cdot 3$ \\
\hline
\end{tabular}

Table 2 Organizational structure of nursing homes

Source: OECD Health Data 1998.

\begin{tabular}{llll}
\hline & Public & $\begin{array}{l}\text { Private } \\
\text { non-profit }\end{array}$ & $\begin{array}{l}\text { Private } \\
\text { for-profit }\end{array}$ \\
\hline Belgium & $40 \% *$ & $40 \% *$ & $20 \%$ * \\
Denmark & $72 \%$ & $28 \%$ & $26 \%$ \\
Germany & $25 \%$ & $49 \%$ & \\
The Netherlands & $<5 \% *$ & $>95 \% *$ & \\
\hline
\end{tabular}

= estimate by expert.

Table 3 Characteristics of nursing homes and patient population

\begin{tabular}{|c|c|c|c|c|}
\hline & Belgium & Denmark $\dagger$ & Germany & The Netherlands \\
\hline Nursing home beds/1000 population in 1994 (OECD 1998) & $1 \cdot 1$ & $6 \cdot 2$ & $0 \cdot 4$ & $3 \cdot 7$ \\
\hline Nursing home beds/\% total bed stock in 1994 (OECD 1998) & $15 \cdot 3$ & n.a. & $39 \cdot 0$ & $31 \cdot 2$ \\
\hline$\%$ Total elderly population over 65 in nursing homes & $1 \cdot 4^{*}$ & $4 \cdot 2$ & $3 \cdot 1$ & $2 \cdot 5$ \\
\hline Average number of beds per nursing home & $30^{*}$ & 39 & 46 & $170 \cdot 8$ \\
\hline Average length of stay patients (years) & $3 \cdot 5^{*}$ & $2 \cdot 8^{3}$ & 3 & $1 \cdot 4$ \\
\hline Average age patients & 82 & n.a. & 81 & 81 \\
\hline$\%$ Female of total nursing home population & 75 & n.a. & $79 \cdot 5$ & $72 \cdot 8$ \\
\hline$\%$ Somatic patients & $70^{*}$ & n.a. & 41 & 52 \\
\hline$\%$ Psycho-geriatric patients & $30^{*}$ & n.a. & 59 & 48 \\
\hline
\end{tabular}

n.a. = not available, no figures recorded on a national level. * Estimate by expert, no figures recorded on a national level. $\dagger$ Figures for traditional nursing homes for $1998 .{ }^{3}$ Figure for nursing homes in the municipality of Copenhagen. 